\title{
Interaction of Temperature and Light in the Development of Freezing Tolerance in Plants
}

\author{
Tibor Janda • Imre Majláth • Gabriella Szalai
}

Received: 15 July 2013/ Accepted: 3 September 2013

(c) Springer Science+Business Media New York 2013

\begin{abstract}
Freezing tolerance is the result of a wide range of physical and biochemical processes, such as the induction of antifreeze proteins, changes in membrane composition, the accumulation of osmoprotectants, and changes in the redox status, which allow plants to function at low temperatures. Even in frost-tolerant species, a certain period of growth at low but nonfreezing temperatures, known as frost or cold hardening, is required for the development of a high level of frost hardiness. It has long been known that frost hardening at low temperature under low light intensity is much less effective than under normal light conditions; it has also been shown that elevated light intensity at normal temperatures may partly replace the cold-hardening period. Earlier results indicated that cold acclimation reflects a response to a chloroplastic redox signal while the effects of excitation pressure extend beyond photosynthetic acclimation, influencing plant morphology and the expression of certain nuclear genes involved in cold acclimation. Recent results have shown that not only are parameters closely linked to the photosynthetic electron transport processes affected by light during hardening at low temperature, but light may also have an influence on the expression level of several other cold-related genes; several cold-acclimation processes can function efficiently only in the presence of light. The present review provides an overview of mechanisms that may explain how light improves the freezing tolerance of plants during the cold-hardening period.
\end{abstract}

T. Janda $(\bowtie) \cdot$ I. Majláth · G. Szalai

Agricultural Institute, Centre for Agricultural Research,

Hungarian Academy of Sciences, POB 19, Martonvásár 2462, Hungary

e-mail: janda.tibor@agrar.mta.hu
Keywords Chloroplast · Cold hardening · Excitation · Freezing · Frost tolerance · Photosynthesis · Plant hormones · Signalling

\section{Introduction}

Low temperature is one of the most important factors in limiting the growth and distribution of plants. The exposure of plants to suboptimal temperatures may cause a reduction of growth, or even lethal stress symptoms. However, growing at low temperature may also have beneficial effects, such as the induction of flowering. This is known as vernalization (reviewed in Srikanth and Schmid 2011) and is required, for example, by the majority of winter cereals. A further benefit may be the development of frost tolerance, which allows plants to survive a subsequent exposure to freezing temperature, a process called cold hardening. The development of a sufficient level of cold hardiness requires prolonged periods of exposure to cold, even in frost-tolerant plants. Cold acclimation includes changes in a wide range of physical and biochemical processes that allow functioning at low temperatures, such as the induction of antifreeze proteins, changes in membrane composition, the accumulation of osmoprotectants, or changes in the redox status of the plant. Protective mechanisms providing a higher level of frost tolerance have also been studied extensively, especially in the model plant Arabidopsis or in winter cereals of great economic importance (Chen and others 2002; Winfield and others 2010; Knight and Knight 2012).

It has long been known that low temperatures are not able to induce frost hardiness in winter annuals in the absence of light (Levitt 1972). Although hardening in the dark increased the survival of winter cereals, it was 
substantially less effective than hardening in the light (Gray and others 1997; Apostol and others 2006). In the case of winter wheat, the lack of a sufficient level of light intensity during the cold-hardening period may cause an even more dramatic reduction in freezing tolerance than the difference between spring and winter varieties (our unpublished data). The positive effect of light on the development of freezing tolerance during the cold-hardening period has been demonstrated not only in monocot cereals but also in dicot Arabidopsis plants (Wanner and Junttila 1999).

Earlier results showed that the photosynthetic adjustment exhibited by cold-hardened plants mimics that exhibited by plants exposed to high light intensity, whereas the photosynthetic response of nonhardened plants is mimicked by that of plants grown at low light intensity. The decisive role of light in the development of freezing tolerance was also indicated by the improvement of freezing tolerance under elevated light conditions without cold treatment (Gray and others 1997). Interestingly, the frost tolerance induced by elevated light intensity at normal growth temperatures was also more pronounced in winter wheat varieties than in spring varieties (Szalai and others 2009a). These results indicate that low temperature and light-induced signalling routes overlap and accelerate each other in the development of freezing tolerance in plants. Recent results show that light may also substantially enhance the induction of a wide range of protective compounds earlier found to be connected with cold-hardening processes (Janda and others 2007; Szalai and others 2009a; Majláth and others 2012). The present review provides an overview of mechanisms that may explain how light improves the freezing tolerance of plants during the coldhardening period.

\section{Involvement of Photosynthetic Electron Transport Processes}

The most obvious candidates for the mechanisms underlying the effect of light on the freezing tolerance of plants are the photosynthetic processes. Decreasing temperatures may diminish the ability of plants to use the absorbed light energy, leading to the overreduction of the photosynthetic electron transport chain, which, in turn, may lead to photoinhibition of Photosystem II (PSII) (Keren and KriegerLiszkay 2011). Cold-acclimated plants have been shown to be less sensitive to photoinhibition due to an increase in their capacity to keep the primary quinone acceptor of PSII oxidized; this appears to correlate with the maximum freezing tolerance of plants (Hurry and Huner 1992; Janda and others 1994). Because the changes taking place in the chloroplast under low-temperature conditions have recently

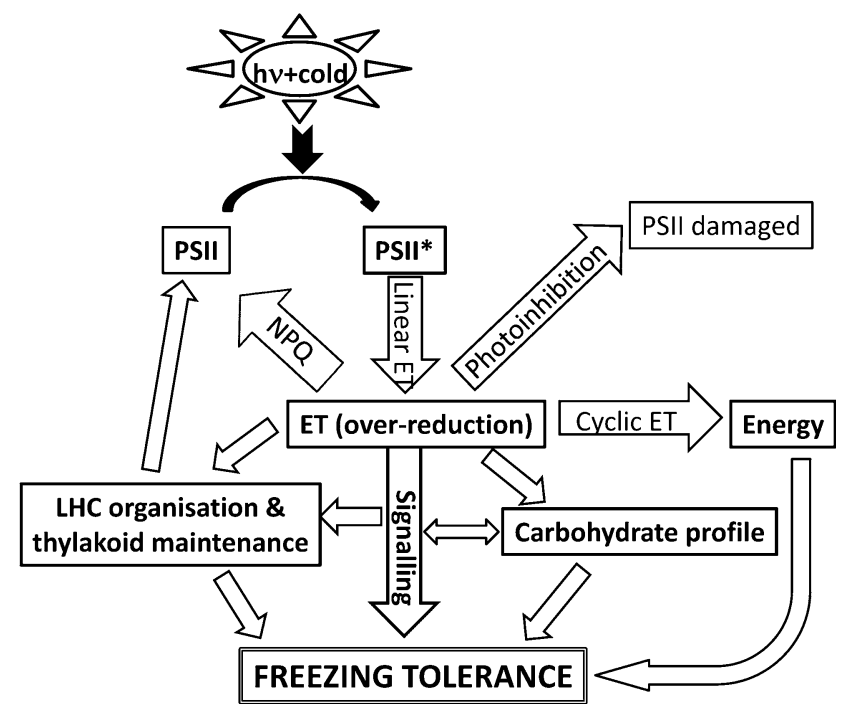

Fig. 1 Involvement of photosynthetic processes in the improvement of freezing tolerance during cold hardening. ET electron transport, $L T$ low temperature. See text for details

been reviewed (Ashraf and Harris 2013; Crosatti and others 2013), the present subchapter focuses on processes that may be directly linked to the light-mediated development of freezing tolerance (Fig. 1).

The potential for an energy imbalance between photochemical processes, electron transport, and metabolism is exacerbated under conditions of either high light intensity or low temperatures, leading to increased excitation pressure in PSII. To compensate for exposure to high PSII excitation pressure, plants attempt to reduce energy transfer efficiency to PSII, either by dissipating excess energy as heat through nonphotochemical fluorescence quenching (NPQ) or by diverting energy from PSII to Photosystem I (PSI). Several changes that play a role in cold acclimation processes are correlated with the relative reduction state of PSII rather than with growth temperature or growth irradiance per se (Gray and others 1997). When Arabidopsis plants were cold acclimated in the presence of 3-(3,4dichlorophenyl)-1,1-dimethylurea (DCMU), which blocks photosynthetic electron transport within PSII between the primary electron acceptor $\mathrm{Q}_{\mathrm{A}}$ and the secondary acceptor $\mathrm{Q}_{\mathrm{B}}$, they failed to harden and were killed by freezing temperatures (Wanner and Junttila 1999). This suggests that the signal for the induction of freezing tolerance is generated not by overreduction within PSII itself, but by electron transport via $\mathrm{Q}_{B}$ or downstream of $\mathrm{Q}_{\mathrm{B}}$. This serves as further direct evidence for the primary role of the photosynthetic electron processes in determining the level of freezing tolerance.

Photosynthesis also provides the energy necessary for the attainment of a cold-acclimated state; thus, any environmental factor that has a negative impact on photosynthesis may ultimately influence the induction of freezing tolerance 
(Ensminger and others 2006). Due to the increased demand for ATP, cyclic electron flow is often triggered in plants under stress conditions (Wang and others 2013). Thermoluminescence studies suggested that the induction of cyclic photosynthetic electron flow, which may contribute to an optimal energy balance during periods of low-temperature stress, may also add to the advantage of frost hardening in the light in wheat plants (Apostol and others 2006).

The expression levels of several photosynthesis-related genes are also affected by the light intensity during the cold-hardening period. The expression of genes encoding various light harvesting complex (LHC) proteins in Arabidopsis plants was strongly enhanced during the coldhardening period in the light, but not in the dark. However, only a few nuclear genes coding for the core proteins of PSII or PSI complexes exhibited light-induced differences in the expression level (Soitamo and others 2008). Similarly, several sequences related to photosynthetic processes were differentially expressed in wheat plants depending on both the light intensity and the level of freezing tolerance of the genotype. For example, although the PSI P700 chlorophyll $a$ apoprotein A1 and the PSII CP43 chlorophyll apoprotein of hardened plants were downregulated at low light intensity, other sequences related to genes encoding chlorophyll $a / b$-binding protein precursors showed higher expression rates under such conditions in winter wheat. In contrast, the expression levels of the chlorophyll-binding proteins in spring wheat were downregulated at low light intensity (Majláth and others 2012). This is in agreement with other results, showing that the chlorophyll-binding proteins remained significantly upregulated in a spring cultivar, whereas in a winter cultivar the expression levels of these genes returned to the control level after a long period of cold acclimation $(\mathrm{Gu}-$ lick and others 2005).

Three genes encoding ATP-dependent, filamentation temperature-sensitive zinc metalloproteases ( $\mathrm{FtsH})$, which are important in chloroplast biogenesis and thylakoid maintenance, were also mainly upregulated at low temperature in the light (Soitamo and others 2008). It is assumed that these enzymes have a role in the repair of PSII after photoinhibition, being involved in the proteolytic removal of an oxidatively damaged, cleaved membrane protein-the PSII reaction center D1 protein-and probably in other proteolytic degradation processes related to protein quality control. FtsH protease may also be associated with the biogenesis of chloroplasts, probably through participation in the formation of thylakoids (Zaltsman and others 2005) and also possibly in the degradation of the LHC proteins. Paradoxically, this means that light may induce the expression of protein, which helps the plant recover from the photodamage induced by light.

\section{Carbohydrates}

Soluble sugars may also act as osmotically active compounds and may increase tolerance to low temperature or drought. The ability to sustain high rates of photosynthesis at low growth temperatures is associated with increases in activity of the enzymes involved in the photosynthetic carbon reduction cycle and sucrose synthesis, and in the ability of cold-hardened leaves to sustain large pools of phosphorylated intermediates (Hurry and others 1995). However, the fact that several single-gene mutants, for example, certain $s f r$ (sensitive to freezing) mutants, accumulated sugars normally or even at elevated levels in response to low temperature but were still defective in freezing tolerance indicates that sugar accumulation alone is insufficient to induce a high level of frost tolerance (McKown and others 1996).

Even though it is generally accepted that low temperature decreases carbon fixation and may inactivate Calvin cycle enzymes in chilling-sensitive plants, no downregulation of Calvin cycle genes was found during cold treatment in chilling-tolerant Arabidopsis plants (Soitamo and others 2008). A rapid accumulation of soluble sugars, such as sucrose, glucose, or fructose, could also be detected during cold hardening in the light, but not in the dark; the deacclimation process may lead to a rapid decline in the total sugar content (Wanner and Junttila 1999; Pagter and others 2011). Furthermore, the small and large subunits of Rubisco were downregulated at low light intensity in spring wheat and after the cold-hardening period in winter wheat varieties, respectively. Light may also play an important regulatory role in the synthesis of fructans, which have been strongly associated with cold stress in cereals, because the expression rate of the fructosyltransferase genes responsible for their synthesis was the most light-dependent in spring wheat (Majláth and others 2012).

\section{Lipid Composition}

Damage to cellular membranes is the major cause of freezing injury in plants, and membrane lipid composition is strongly modified during cold acclimation. An increasing level of lipid unsaturation is a general response to decreasing temperatures in various living organisms. The relative abundance of certain lipid species was closely correlated with freezing tolerance in various plant species, allowing the identification of possible marker lipids for plant freezing tolerance (Szalai and others 2001; Degenkolbe and others 2012). However, recent results also show that light may affect the changes taking place in lipid composition during the cold-hardening period. For example, significant differences in the lipid composition of the 
phosphatidylethanolamine (PE) fraction could be detected in winter wheat leaves when hardening was carried out under different light conditions. A drop in the 16:0 and 18:0 contents of PE with a concomitant increase in the 18:3 content, leading to a significant increase in the double-bond index, could be observed only in plants that were cold hardened at low temperature in the light, but not in the dark (Janda and others 2007).

The cold hardening of cereals may also cause changes in the phosphatidylglycerol (PG) lipid fraction, including trans- $\Delta 3$-hexadecenoic acid (t16:1), which contributes to maintaining the thylakoid membrane organization of proteins and pigments and the optimal conformation of the D1 protein, stabilizing the photosystem complexes, and facilitating efficient linear electron flow (Kruse and others 2000). A strong direct relationship between freezing tolerance and the capacity to change the t16:1 content of PG in response to low-growth temperature could be observed only in cereals, whereas in cold-tolerant dicotyledonous plants this mechanism was not general (Huner and others 1989). The analysis of the lipid composition of coldhardened winter wheat plants showed that the saturation level of t16:1 decreased not only in plants hardened at low temperature, but also, to a lesser degree, in plants kept at high irradiation levels. This means that the regulation of LHC organization by changes in the t16:1 content of PG in cereals is caused not only by low temperature but also by excitation pressure and may contribute to the enhanced freezing tolerance induced by high light intensity at nonhardening temperatures. However, because the coldinduced drop in the t16:1 content of PG could not usually be observed in various cold-tolerant dicotyledonous species (Huner and others 1989) and because similar changes have also been shown in cold-sensitive maize plants exposed to the heavy metal cadmium (Pál and others 2007), it appears that this effect is not the main factor in the contribution of light to improved freezing tolerance, but rather a general stress response.

\section{Effect of Light at the Gene Expression Level}

Cold-induced genes have been isolated and characterized in many species, and there is a close correlation between the expression of some of these genes and the development of freezing tolerance (Guy 1990; Howarth and Ougham 1993). Recent results suggest that light has a significant effect on the expression level of several genes during the cold acclimation period in plants (Ndong and others 2001; Soitamo and others 2008; Majláth and others 2012). Cold treatment in the light upregulated twice as many genes in Arabidopsis plants as cold treatment in the dark, whereas only a combination of light and low temperature enhanced the expression of several genes earlier described as cold-responsive genes (Soitamo and others 2008). Similar tendencies were found in coldhardened wheat plants; however, significant differences could be detected in the light responses of several genes in winter and spring varieties with different levels of frost tolerance (Majláth and others 2012).

The expression of genes encoding certain subunits of nuclear factor Y (NF-Y), potentially involved in the regulation of photosynthesis-related genes, was also upregulated by light in wheat leaves (Stephenson and others 2010). Besides its role in osmoregulation under stress conditions, sugar metabolism is yet another potential source for the regulation of nuclear genes (Sheen and others 1999; Xiao and others 2000) and is likely to cause major changes in gene expression during cold hardening under different light conditions. The effect of signalling sugar molecules on nuclear gene expression might be exerted via Dof (DNA binding with one finger) domain transcription factors or the WRKY protein SPF1. It has also been shown that the overexpression of a salicylic acid (SA)-inducible Dof transcription factor (OBP3) resulted in growth defects in Arabidopsis plants (Kang and Singh 2000). Because light has also been shown to affect SA metabolism during cold hardening, which together with its putative precursor ortho-hydroxycinnamic acid has also been implicated in the development of cold tolerance (Horváth and others 2007a, b; Janda and others 2007; Sasheva and others 2010), it can be assumed that Dof elements may also play a role in the growth regulation induced by low temperature.

Besides genes directly related to components in the photosynthetic machinery, the expression level of several genes encoding various kinds of transcription factors may also depend on light intensity during the cold-hardening period. Earlier results showed that the expression of the wcs 19 (wheat cold-stimulated) gene encoding a chloroplast stromal late embryogenesis abundant-like protein, which had been previously associated with cold acclimation and may protect cold-acclimated leaves from freeze-induced damage (Ndong and others 2002), was also correlated with the relative reduction state of PSII (Gray and others 1997). In Arabidopsis plants more than 40 differentially regulated transcription factors were found during cold acclimation under different light conditions. Genes induced by cold treatment in the light also included both cold-responsive and zinc-finger, myeloblastosis (MYB), NAC, or Apetala 2 (AP2) domains containing transcription factors, which are likely to function in concert in enhancing gene expression (Soitamo and others 2008). Similar response elements were found in the promoter regions of both the transcription factors and their target genes, implying the possible parallel regulation or amplification of environmental signals, depending on the metabolic/redox state in the cells. 


\section{Plant Growth Regulators}

The hormonal regulation of development is a complex process involving interactions between various hormones at the transcriptional, translational, and cellular levels (Chandler 2009). During growth at low temperatures, the regulation of plant size is accompanied by the expression of genes involved in cold acclimation (Patel and Franklin 2009). The adjustment of hormone levels is an important part of cold acclimation in plants (Kosová and others 2012). Among the hormones, auxin controls essentially all aspects of plant development, from embryogenesis to senescence. By regulating a group of primary responsive genes at the transcriptional level, auxins act as a central part of the hormonal crosstalk mediating the stress response (Swarup and others 2002; Chandler 2009; Depuydt and Hardtke 2011; Hagen and Guilfoyle 2002). Recent work on wheat plants indicated that light may also influence levels of certain plant hormones during low-temperature hardening. Light intensity was found to have a pivotal role in determining the auxin level in winter wheat plants during cold hardening, with a significantly higher auxin level being detected when plants were grown at normal light than at low light intensity. It can be assumed that auxins promote a continuous but moderate rate of growth in winter wheat at low temperatures (Majláth and others 2012).

The function of ethylene in cold acclimation may involve the induction of antifreeze protein accumulation in plants ( $\mathrm{Yu}$ and others 2001). Ethylene has a complex interaction with auxin (Rahman 2013). They show both synergistic and antagonistic interactions in regulating various developmental processes such as apical hook formation, root and shoot elongation, root and shoot gravitropism, lateral root development, root hair initiation and elongation, hypocotyl phototropism, and leaf abscission. These interactions are regulated at the biosynthesis level (Muday and others 2012). It was reported that ethylene negatively regulates plant responses to freezing stress in Arabidopsis thaliana. Freezing tolerance decreased in ethylene-overproducing plants or in response to the application of the ethylene precursor 1-aminocyclopropane-1carboxylic acid (ACC), but it increased after the addition of the ethylene biosynthesis inhibitor aminoethoxyvinylglycine or the perception antagonist $\mathrm{Ag}^{+}$. Furthermore, ethylene-insensitive mutants displayed enhanced freezing tolerance. By contrast, constitutive ethylene response mutants exhibited reduced freezing tolerance (Shi and others 2012). The changes in the content of ACC and the auxin level were similar after cold hardening, which might indicate intensive crosstalk between auxin and ethylene via the stimulation of ACC synthase (Majláth and others 2012).
Cytokinins (CK) have also been shown to control the transcription of photosynthesis-related genes in a lightdependent manner (Boonman and others 2007). It seems that CK signalling might be suppressed soon after transfer to low temperature. As shown in Arabidopsis plants, cold may induce the expression of a subset of type A response regulator genes (ARR; negative regulators of CK signalling) (Jeon and others 2010). The cold signal may be perceived directly by the histidine kinases AHK2 and AHK3, but it is more likely to act indirectly, perhaps through a change in membrane rigidity (Jeon and Kim 2013). Crosstalk between light and CK signalling, mediated by the A-type response regulator ARR4, has also been described. ARR4 is activated by phosphorylation in a process triggered by the CK receptors. Active ARR4 is able to interact with and stabilize the active Pfr form of the red light photoreceptor phytochrome B (Mira-Rodado and others 2007). CK-activated ARR2 has also been shown to promote plant immunity via SA signalling in Arabidopsis (Choi and others 2010). In winter wheat, a highly significant rise in the $\mathrm{CK}$ storage compounds (CK $O$-glucosides) was also detected during the cold-hardening period, and this rise was more pronounced in the light than in the dark (Majláth and others 2012).

The key hormone in the response to various abiotic stressors is abscisic acid (ABA) (Rahman 2013), which plays an essential role in plant responses to abiotic stresses, including chilling, salinity, high temperature, and drought. The adaptation of plants to these environmental stresses is associated with increases in the ABA level (Zhu 2002). It was found that ABA signal transduction can occur through various combinations of proteins. The current model of ABA signal transduction suggests that PYR/PYL/RCAR act as ABA receptors, whereas PP2Cs act as negative regulators and SnRK2s act as positive regulators of downstream signalling. A double-negative regulatory pathway has been hypothesized, whereby ABA-bound RCARs inhibit PP2C activity and PP2Cs inactivate SnRK2s (Cutler and others 2010). In grape, as in Arabidopsis, ABA signal transduction can occur through various combinations of proteins. A total of 48 different combinations of interactions between two signal transduction components have been identified. Although the large number of ABA signalosome variants could lead to a wide range of ABA responses in plants, actual in vivo combinations may be somewhat limited due to multiple determinants, such as tissue or organ specificities, stressresponsive gene expression patterns, subcellular localization, and preferences in protein-protein interactions (Boneh and others 2012). The ability of the plant to choose between alternate pathways may allow it to fit its response to the specific environmental challenge. Interacting with other plant growth regulators, $\mathrm{ABA}$ plays a critical role in 
the regulation of the plant's water balance under unfavorable environmental conditions (Finkelstein and others 2002). Experiments with ABA-mutant Arabidopsis plants suggested that some cold-induced genes are activated through an ABA-dependent and others through an ABAindependent pathway (Thomashow 1999; Xiong and others 2002; Shinozaki and Shinozaki 2006). ABA seems to contribute to enhanced tolerance of suboptimal temperature and to the indirect control of the endogenous ethylene level in tomato plants (Ntatsi and others 2013). The gene expression of ABA biosynthetic enzymes, such as zeaxanthin epoxidase, was specifically upregulated only under light conditions in Arabidopsis (Soitamo and others 2008), whereas aldehyde oxidase 2 was downregulated at low light intensity in winter wheat at low temperature (Majláth and others 2012).

\section{Synthesis of Protective Compounds Under Different Light Conditions}

Antioxidative systems, including both nonenzymatic (ascorbic acid, glutathione, and so on) and enzymatic compounds, also play a role in the adjustment of the cellular redox state, in redox signalling, and in orchestrating the expression of genes taking part in the stress acclimation processes (Noctor and Foyer 1998; Noctor 2006; Szalai and others 2009b; Kocsy and others 2011). Freezing tolerance may also be associated with oxidative stress, and cold acclimation may induce the synthesis of antioxidative compounds, including antioxidant enzymes (Janda and others 2003). During the cold-hardening period the enzymes glutathione reductase, glutathione- $S$-transferase, and ascorbate peroxidase were induced to the greatest extent when the cold treatment was carried out in normal light, but the activity of these enzymes was also increased by elevated light intensity at normal, nonhardening temperature in wheat plants (Janda and others 2007; Szalai and others 2009a). The light-dependent upregulation of genes encoding chloroplast ROS-scavenging proteins, such as an iron superoxide dismutase and two glutathione-dependent peroxidases, was also detected in Arabidopsis plants (Soitamo and others 2008).

Proline accumulation is a common physiological response of plants to several stressors such as drought, salinity, or temperature. Proline may function as a compatible osmolyte, act as an energy source or a ROS scavenger, and possibly play a role as a molecular chaperon. During exposure to low temperatures, proline accumulation could be detected only under light conditions, as reported in various plant species such as citrus plants (Yelenosky 1979) and wheat (Majláth and others 2012). Similarly, saltinduced proline accumulation was also more effective in the light than in the dark (Ábrahám and others 2003). A close relationship between leaf dehydrin content and freezing tolerance was observed for various plant species, such as barley (Kosová and others 2008, 2010), wheat (Vítámvás and others 2007, 2010), and olive (Cansev and others 2009). Accordingly, the basal expression level of dehydrin genes was significantly higher in winter wheat, which has a high level of frost tolerance than spring wheat (Majláth and others 2012). The light-dependent accumulation of dehydrin at low temperature was also reported in several Brassica genotypes, where greater dehydrin accumulation was observed at higher irradiance (Klíma and others 2012).

Besides proline, glycinebetaine (GB), which is a fully $N$ methyl-substituted derivative of glycine, also acts as an important defense compound during exposure to various stressors such as cold and light (Giri 2011). Arabidopsis plants with the cloned $\operatorname{codA}$ (a bacterial choline oxidase) gene are able to accumulate GB, thus enhancing tolerance to salt and cold stress. Leaves of wild-type plants exposed to low temperature in the light exhibited symptoms of chlorosis, whereas those of transformed plants did not (Hayashi and others 1997). The enhanced ability of transformed plants to tolerate the photo-induced inactivation of the PSII complex might be due to the acceleration of the recovery process. In other experiments, transgenic tobacco plants cloned with the choline dehydrogenase or betaine aldehyde dehydrogenase genes were exposed to low temperature in the light. The maximum quantum efficiency of PSII in the wild-type plants showed a more pronounced decrease than in the transgenic lines. On the other hand, no difference was found in the net photosynthesis under ambient conditions between the transgenic lines and wildtype plants (Holmström and others 2000).

A decrease in temperature may induce the genes responsible for the synthesis of polyamines, which may also play an important role in acclimation processes by participating in the modification of chromatin structure, gene transcription and translation, DNA stabilization, signal transduction, cell growth and proliferation, migration, membrane stability, the functioning of ion channels, and receptor-ligand interactions. It has also been shown that changes in the polyamine contents during low-temperature hardening of spring or winter wheat plants were dependent not only on the genotype but also on the light. Although the level of diamine putrescine substantially increased in winter wheat when cold hardening was carried out under normal light conditions, it decreased at low temperature at low light intensity. The content of spermidine, a triamine synthesized from putrescine, which may play a regulatory role in stress signalling pathways, did not change at low temperature in the dark but increased in the light. The fact that low-temperature stress in the light may also lead to an 
Fig. 2 Light-mediated signalling processes in plants during the cold hardening period. See text for details

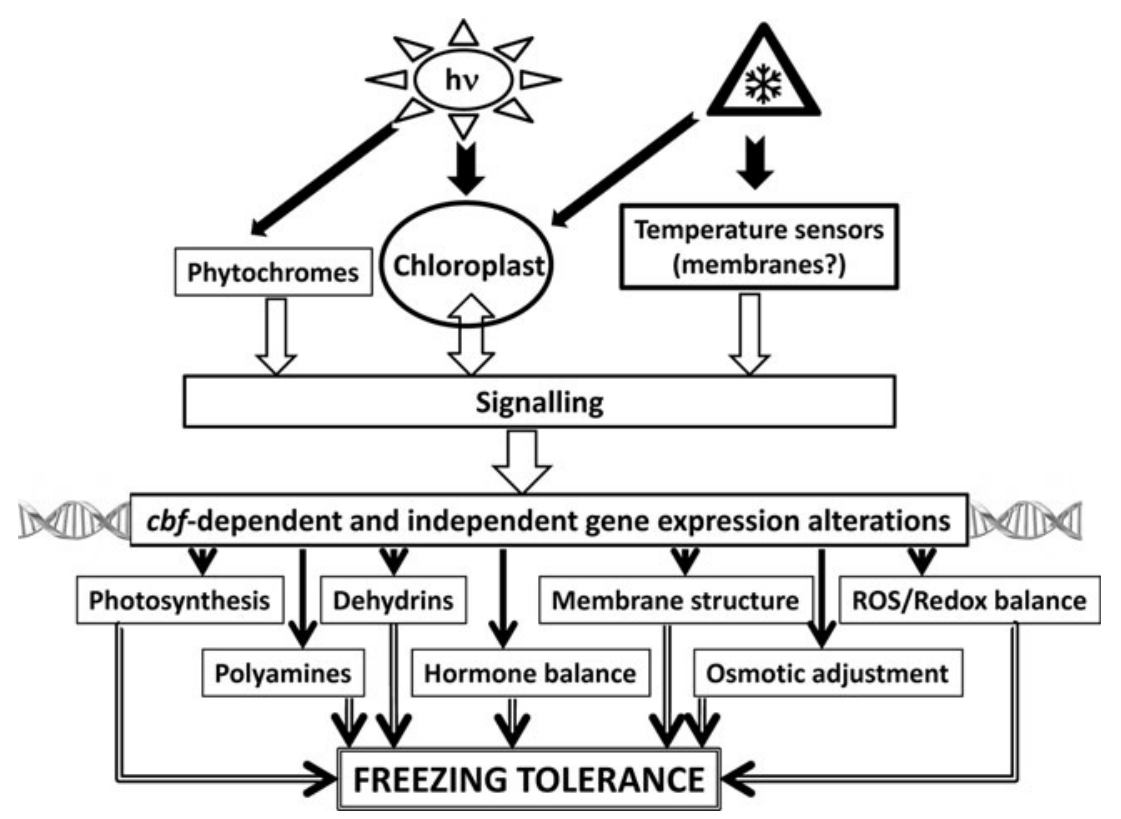

increased putrescine level in chilling-sensitive plants suggests that changes in the putrescine level are not directly related to freezing tolerance but are part of a general adaptation process that may reduce the damaging effect of cold-induced photoinhibition. Low temperature in the light may also induce the synthesis of another polyamine, cadaverine, which is synthesized independent of the putrescine-spermidine-spermine pathway and is thought to act as a free radical scavenger (Szalai and others 2009a).

\section{Light Quantity or Quality?}

The above-mentioned results indicate that light quantity during the cold-hardening period substantially determines the level of freezing tolerance acquired, and that a redox signal originating from the chloroplasts may be the main factor in the contribution of light to the improvement of freezing tolerance (Crosatti and others 2013). Although the sensing and signalling events in photomorphogenic development are typically associated with photoreceptors, compact growth morphology can also be induced simply by lowering the temperature without changes in either light quality or photoperiod (Huner and others 1998). However, recent results suggest that light quality (the red:far-red ratio) and the photoperiod may also have an appreciable impact on the signalling processes leading to freezing tolerance in plants (recently reviewed by Maibam and others 2013).

The P730 form of phytochrome B could also be involved in triggering the pathway of signal transduction and enhancing the expression of the $c b f$ genes (Kim and others 2002). Lower temperatures and the wavelength alterations caused by longer twilight periods during the autumn months at northern latitudes may provide some cold-related (COR) gene induction, thereby protecting plants against sudden decreases in temperature (Franklin and Whitelam 2007; Franklin 2009). Recent results also show that during a warm, long-day growing season the CBF pathway is actively repressed by phytochrome-interacting factors PIF4 and PIF7, reducing the allocation of energy and nutrient resources to unneeded frost protection (Lee and Thomashow 2012).

\section{Conclusions}

During the exposure of plants to low temperature, light has two opposing faces: on the one hand, it induces photoinhibition, but on the other hand, it is essential for the development of freezing tolerance. The development of freezing tolerance during the cold-hardening period can no longer be viewed only from the perspective of temperature changes; it is also necessary to consider light responses. Recent results indicate that several kinds of biological processes, including the expression of genes earlier described as cold-responsive, might contribute to lightinduced freezing tolerance in plants (Fig. 2). Processes related to photosynthesis probably play a key role in the enhancement of freezing tolerance; however, the expression level of several other stress-related genes and the synthesis of various protective compounds are also lightdependent, so either there is crosstalk between signalling of chloroplast origin and other protective mechanisms, and/or there are other light sensors that transduce signals to the components responsible for stress tolerance. Although 
there are still several open questions in this field, understanding the mechanisms by which plants perceive environmental signals and transmit them to the cellular machinery to activate adaptive responses is of fundamental importance and could help to develop crops capable of tolerating environmental changes with as little damage as possible.

Acknowledgments This work was supported by OTKA 104963. Thanks to Barbara Harasztos for revising the English.

\section{References}

Ábrahám E, Rigó G, Székely G, Nagy R, Koncz C, Szabados L (2003) Light-dependent induction of proline biosynthesis by abscisic acid and salt stress is inhibited by brassinosteroid in Arabidopsis. Plant Mol Biol 51:363-372

Apostol S, Szalai G, Sujbert L, Popova LP, Janda T (2006) Noninvasive monitoring of the light-induced cyclic photosynthetic electron flow during cold hardening in wheat leaves. Z Naturforsch C 61:734-740

Ashraf M, Harris PJC (2013) Photosynthesis under stressful environments: an overview. Photosynthetica 51:163-190

Boneh U, Biton I, Schwartz A, Ben-Ari G (2012) Characterization of the ABA signal transduction pathway in Vitis vinifera. Plant Sci 187:89-96

Boonman A, Prinsen E, Gilmer F, Schurr U, Peeters AJM, Voesenek LACJ, Pons TL (2007) Cytokinin import rate as a signal for photosynthetic acclimation to canopy light gradients. Plant Physiol 143:1841-1852

Cansev A, Gulen H, Eris A (2009) Cold-hardiness of olive (Olea europaea L.) cultivars in cold-acclimated and non-acclimated stages: seasonal alteration of antioxidative enzymes and dehydrin-like proteins. J Agric Sci 147:51-61

Chandler JW (2009) Auxin as compère in plant hormone crosstalk. Planta 231:1-12

Chen WQ, Provart NJ, Glazebrook J, Katagiri F, Chang HS, Eulgem T, Mauch F, Luan S, Zou GZ, Whitham SA, Budworth PR, Tao Y, Xie ZY, Chen X, Lam S, Kreps JA, Harper JF, Si-Ammour A, Mauch-Mani B, Heinlein M, Kobayashi K, Hohn T, Dang JL, Wang X, Zhu T (2002) Expression profile matrix of Arabidopsis transcription factor genes suggests their putative functions in response to environmental stresses. Plant Cell 14:559-574

Choi J, Huh SU, Kojima M, Sakakibara H, Paek KH, Hwang I (2010) The cytokinin-activated transcription factor ARR2 promotes plant immunity via TGA3/NPR1-dependent salicylic acid signaling in Arabidopsis. Dev Cell 19:284-295

Crosatti C, Rizza F, Badeck FW, Mazzucotelli E, Cattivelli L (2013) Harden the chloroplast to protect the plant. Physiol Plant 147(1):55-63

Cutler SR, Rodriguez PL, Finkelstein RR, Abrams SR (2010) Abscisic acid: emergence of a core signalling network. Annu Rev Plant Biol 61:651-679

Degenkolbe T, Giavalisco P, Zuther E, Seiwert B, Hincha DK, Dirk K, Willmitzer L (2012) Differential remodeling of the lipidome during cold acclimation in natural accessions of Arabidopsis thaliana. Plant J 72:972-982

Depuydt S, Hardtke CS (2011) Hormone signalling crosstalk in plant growth regulation. Curr Biol 21:R365-R373

Ensminger I, Busch F, Huner NPA (2006) Photostasis and cold acclimation: sensing low temperature through photosynthesis. Physiol Plant 126:28-44
Finkelstein RR, Gampala SSL, Rock CD (2002) Abscisic acid signalling in seeds and seedlings. Plant Cell 14:515-545

Franklin KA (2009) Light and temperature signal crosstalk in plant development. Curr Opin Plant Biol 12:63-68

Franklin KA, Whitelam GC (2007) Light-quality regulation of freezing tolerance in Arabidopsis thaliana. Nat Genet 39: $1410-1413$

Giri J (2011) Glycinebetaine and abiotic stress tolerance in plants. Plant Signal Behav 6(11):1746-1751

Gray GR, Chauvin LP, Sarhan F, Huner N (1997) Cold acclimation and freezing tolerance (a complex interaction of light and temperature). Plant Physiol 114:467-474

Gulick PJ, Drouin S, Yu Z, Danyluk J, Poisson G, Monroy AF, Sarhan F (2005) Transcriptome comparison of winter and spring wheat responding to low temperature. Genome 48:913-923

Guy CL (1990) Cold acclimation and freezing stress tolerance: role of protein metabolism. Annu Rev Plant Physiol Plant Mol Biol 41:187-223

Hagen G, Guilfoyle T (2002) Auxin-responsive gene expression: genes, promoters, and regulatory factors. Plant Mol Biol 49:373-385

Hayashi H, Alia, Mustardy L, Deshnium P, Ida M, Murata N (1997) Transformation of Arabidopsis thaliana with the codA gene for choline oxidase; accumulation of glycinebetaine and enhanced tolerance to salt and cold stress. Plant J 12(1):133-142

Holmström KO, Somersalo S, Mandal A, Palva TE, Welin B (2000) Improved tolerance to salinity and low temperature in transgenic tobacco producing glycine betaine. J Exp Bot 51(343):177-185

Horváth E, Pál M, Szalai G, Páldi E, Janda T (2007a) Exogenous 4-hydroxybenzoic acid and salicylic acid modulate the effect of short-term drought and freezing stress on wheat (Triticum aestivum L.) plants. Biol Plant 51:480-487

Horváth E, Szalai G, Janda T (2007b) Induction of abiotic stress tolerance by salicylic acid signaling. J Plant Growth Regul 26:290-300

Howarth CJ, Ougham HJ (1993) Gene expression under temperature stress. New Phytol 125:1-26

Huner NPA, Williams JP, Maissan EE, Myscich EG, Krol M, Laroche A, Singh J (1989) Low temperature-induced decrease in trans$\Delta 3$-hexadecenoic acid content is correlated with freezing tolerance in cereals. Plant Physiol 89:144-150

Huner NPA, Öquist G, Sarhan F (1998) Energy balance and acclimation to light and cold. Trends Plant Sci 3(6):224-230

Hurry VM, Huner NP (1992) Effect of cold hardening on sensitivity of winter and spring wheat leaves to short-term photoinhibition and recovery of photosynthesis. Plant Physiol 100(3):1283-1290

Hurry VM, Strand A, Tobiaeson M, Gardeström P, Öquist G (1995) Cold hardening of spring and winter wheat and rape results in differential effects on growth, carbon metabolism, and carbohydrate content. Plant Physiol 109:697-706

Janda T, Kissimon J, Szigeti Z, Veisz O, Páldi E (1994) Characterization of cold hardening in wheat using fluorescence induction parameters. J Plant Physiol 143:385-388

Janda T, Szalai G, Rios-Gonzalez K, Veisz O, Páldi E (2003) Comparative study of frost tolerance and antioxidant activity in cereals. Plant Sci 164:301-306

Janda T, Szalai G, Leskó K, Yordanova R, Apostol S, Popova LP (2007) Factors contributing to enhanced freezing tolerance in wheat during frost hardening in the light. Phytochemistry 68:1674-1682

Jeon J, Kim J (2013) Arabidopsis response regulator1 and Arabidopsis histidine phosphotransfer protein2 (AHP2), AHP3, and AHP5 function in cold signaling. Plant Physiol 161:408-424

Jeon J, Kim NY, Kim S, Kang NY, Novák O, Ku SJ, Cho C, Lee DJ, Lee EJ, Strnad M, Kim J (2010) A subset of cytokinin twocomponent signaling system plays a role in cold temperature stress response in Arabidopsis. J Biol Chem 285:23369-23384 
Kang HG, Singh KB (2000) Characterization of salicylic acidresponsive, Arabidopsis Dof domain proteins: overexpression of OBP3 leads to growth defects. Plant J 21:329-339

Keren N, Krieger-Liszkay A (2011) Photoinhibition: molecular mechanisms and physiological significance. Physiol Plant 142:1-5

Kim HJ, Kim YK, Park JY, Kim J (2002) Light signalling mediated by phytochrome plays an important role in cold-induced gene expression through the $\mathrm{C}$ repeat/dehydration responsive element (C/DRE) in Arabidopsis thaliana. Plant J 29:693-704

Klíma M, Vítámvás P, Zelenková S, Vyvadilová M, Prášil IT (2012) Dehydrin and proline content in Brassica napus and B. carinata under cold stress at two irradiances. Biol Plant 56:157-161

Knight MR, Knight H (2012) Low-temperature perception leading to gene expression and cold tolerance in higher plants. New Phytol 195:737-751

Kocsy G, Pál M, Soltész A, Szalai G, Boldizsár Á, Kovács V, Janda T (2011) Low temperature and oxidative stress in cereals. Acta Agron Hung 59:169-189

Kosová K, Holková L, Prášil IT, Prášilová P, Bradáčová M, Vítámvás P, Čapková V (2008) The expression of dehydrin5 during the development of frost tolerance in barley (Hordeum vulgare). J Plant Physiol 165:1142-1151

Kosová K, Prášil IT, Prášilová P, Vítámvás P, Chrpová J (2010) The development of frost tolerance and DHN5 protein accumulation in barley (Hordeum vulgare) doubled haploid lines derived from Atlas68 $\times$ Igri cross during cold acclimation. J Plant Physiol 167:343-350

Kosová K, Prasil IT, Vitamvas P, Dobrev P, Motyka V, Flokova K, Novak O, Turecková V, Rolcik J, Pesek B, Travnickova A, Gaudinova A, Galiba G, Janda T, Vlasakova E, Prasilova P, Vankova R (2012) Complex phytohormone responses during the cold acclimation of two wheat cultivars differing in cold tolerance, winter Samanta and spring Sandra. J Plant Physiol 169:567-576

Kruse O, Hankamer B, Konczak C, Gerle C, Morris E, Radunz A, Schmid GH, Barber J (2000) Phosphatidylglycerol is involved in the dimerization of photosystem II. J Biol Chem 275:6509-6514

Lee CM, Thomashow MF (2012) Photoperiodic regulation of the C-repeat binding factor (CBF) cold acclimation pathway and freezing tolerance in Arabidopsis thaliana. Proc Natl Acad Sci USA 109:15054-15059

Levitt J (1972) Freezing resistance: types, measurements, and changes. In: Kozlowski TT (ed) Responses of plants to environmental stresses. Academic Press, New York, pp 75-109

Maibam P, Nawkar GM, Park JH, Sahi VP, Lee SY, Kang CH (2013) The influence of light quality, circadian rhythm, and photoperiod on the CBF-mediated freezing tolerance. Int $\mathrm{J}$ Mol Sci 14:11527-11543

Majláth I, Szalai G, Soós V, Sebestyén E, Balázs E, Vanková R, Dobrev PI, Tandori J, Janda T (2012) Effect of light on the gene expression and hormonal status of winter and spring wheat plants during cold hardening. Physiol Plant 145:296-314

McKown R, Kuroki G, Warren G (1996) Cold responses of Arabidopsis mutants impaired in freezing tolerance. J Exp Bot 47:1919-1925

Mira-Rodado V, Sweere U, Grefen C, Kunkel T, Fejes E, Nagy F, Schafer E, Harter K (2007) Functional cross-talk between twocomponent and phytochrome B signal transduction in Arabidopsis. J Exp Bot 58:2595-2607

Muday GK, Rahman A, Binder B (2012) Auxin and ethylene: collaborators or competitors? Trends Plant Sci 17:181-195

Ndong C, Danyluk J, Huner NPA, Sarhan F (2001) Survey of gene expression in winter rye during changes in growth temperature, irradiance or excitation pressure. Plant Mol Biol 45:691-703
Ndong C, Danyluk J, Kenneth E, Wilson KE, Tessa Pocock T, Huner NPA, Sarhan F (2002) Cold-regulated cereal chloroplast late embryogenesis abundant-like proteins. Molecular characterization and functional analyses. Plant Physiol 129:1368-1381

Noctor G (2006) Metabolic signalling in defence and stress: the central role of soluble redox couples. Plant Cell Environ 29:409-425

Noctor G, Foyer CH (1998) Ascorbate and glutathione: keeping active oxygen under control. Annu Rev Plant Physiol Plant Mol Biol 49:249-279

Ntatsi G, Savvas D, Druege U, Schwarz D (2013) Contribution of phytohormones in alleviating the impact of sub-optimal temperature stress on grafted tomato. Sci Hortic 149:28-38

Pagter M, Lefevre I, Arora R, Hausman JF (2011) Quantitative and qualitative changes in carbohydrates associated with spring deacclimation in contrasting Hydrangea species. Environ Exp Bot 72:358-367

Pál M, Leskó K, Janda T, Páldi E, Szalai G (2007) Cadmium-induced changes in the membrane lipid composition of maize plants. Cereal Res Commun 35:1631-1642

Patel D, Franklin KA (2009) Temperature-regulation of plant architecture. Plant Signal Behav 4:577-579

Rahman A (2013) Auxin: a regulator of cold stress response. Physiol Plant 147:28-35

Sasheva P, Szalai G, Janda T, Popova L (2010) Study of the behaviour of antioxidant enzymes in the response to hardening and freezing stress in two wheat (Triticum aestivum L.) varieties. C R Acad Bulg Sci 63:1733-1740

Sheen J, Zhou L, Jang JC (1999) Sugars as signaling molecules. Curr Opin Plant Biol 2:410-418

Shi Y, Tian S, Hou L, Huang X, Zhang X, Guo H, Yang S (2012) Ethylene signaling negatively regulates freezing tolerance by repressing expression of $\mathrm{CBF}$ and type-A ARR genes in Arabidopsis. Plant Cell 24:2578-2595

Shinozaki KY, Shinozaki K (2006) Transcriptional regulatory networks in cellular responses and tolerance to dehydration and cold stresses. Annu Rev Plant Biol 57:781-803

Soitamo AJ, Piippo M, Allahverdiyeva Y, Battchikova N, Aro EM (2008) Light has a specific role in modulating Arabidopsis gene expression at low temperature. BMC Plant Biol 8:13

Srikanth A, Schmid M (2011) Regulation of flowering time: all roads lead to Rome. Cell Mol Life Sci 68:2013-2037

Stephenson TJ, McIntyre CL, Collet C, Xue GP (2010) TaNF-YC11, one of the light-upregulated NF-YC members in Triticum aestivum, is co-regulated with photosynthesis-related genes. Funct Integr Genomics 10:265-276

Swarup R, Parry G, Graham N, Allen T, Bennett M (2002) Auxin cross-talk: integration of signalling pathways to control plant development. Plant Mol Biol 49:411-426

Szalai G, Janda T, Páldi E, Dubacq J-P (2001) Changes in the fatty acid unsaturation after hardening in wheat chromosome substitution lines with different cold tolerance. J Plant Physiol 158:663-666

Szalai G, Pap M, Janda T (2009a) Light-induced frost tolerance differs in winter and spring wheat plants. J Plant Physiol 166:1826-1831

Szalai G, Kellos T, Galiba G, Kocsy G (2009b) Glutathione as an antioxidant and regulatory molecule in plants under abiotic stress conditions. J Plant Growth Regul 28:66-80

Thomashow MF (1999) Plant cold acclimation: freezing tolerance genes and regulatory mechanisms. Annu Rev Plant Physiol Plant Mol Biol 50:571-599

Vítámvás P, Saalbach G, Prášil IT, Čapková V, Opatrná J, Jahoor A (2007) WCS120 protein family and proteins soluble upon boiling in cold-acclimated winter wheat. J Plant Physiol 164:1197-1207 
Vítámvás P, Kosová K, Prášilová P, Prášil IT (2010) Accumulation of WCS120 protein in wheat cultivars grown at $9{ }^{\circ} \mathrm{C}$ or $17{ }^{\circ} \mathrm{C}$ in relation to their winter survival. Plant Breed 129:611-616

Wang JH, Li SC, Sun M, Huang W, Cao H, Xu F, Zhou NN, Zhang SB (2013) Differences in the stimulation of cyclic electron flow in two tropical ferns under water stress are related to leaf anatomy. Physiol Plant 147:283-295

Wanner LA, Junttila O (1999) Cold-induced freezing tolerance in Arabidopsis. Plant Physiol 120:391-400

Winfield MO, Lu C, Wilson ID, Coghill JA, Edwards KJ (2010) Plant responses to cold: transcriptome analysis of wheat. Plant Biotechnol J 8:749-771

Xiao W, Sheen J, Jang JC (2000) The role of hexokinase in plant sugar signal transduction and growth and development. Plant Mol Biol 44:451-461
Xiong L, Schumaker KS, Zhu JK (2002) Cell signaling during cold, drought, and salt stress. Plant Cell 14(suppl):S165-S183

Yelenosky G (1979) Accumulation of free proline in citrus leaves during cold hardening of young trees in controlled temperature regimes. Plant Physiol 64:425-427

Yu XM, Griffith M, Wiseman SB (2001) Ethylene induces antifreeze activity in winter rye leaves. Plant Physiol 126:1232-1240

Zaltsman A, Ori N, Adam Z (2005) Two types of FtsH protease subunits are required for chloroplast biogenesis and photosystem II repair in Arabidopsis. Plant Cell 17:2782-2790

Zhu JK (2002) Salt and drought stress signal transduction in plants. Annu Rev Plant Biol 53:247-273 